\title{
Design and Analysis of Steering and Lifting Mechanisms for Forestry Vehicle Chassis
}

\author{
Wenhao Li $\mathbb{D}^{1,2}$ and Feng Kang $\mathbb{D}^{1,2}$ \\ ${ }^{1}$ School of Technology, Beijing Forestry University, No. 35 Tsinghua East Road, Haidian District, Beijing 100083, China \\ ${ }^{2}$ Key Laboratory of State Forestry Administration on Forestry Equipment and Automation, \\ No. 35 Tsinghua East Road, Haidian District, Beijing 100083, China \\ Correspondence should be addressed to Feng Kang; kangfeng98@bjfu.edu.cn
}

Received 30 August 2019; Revised 15 December 2019; Accepted 6 February 2020; Published 12 March 2020

Academic Editor: Ioannis Kostavelis

Copyright (c) 2020 Wenhao Li and Feng Kang. This is an open access article distributed under the Creative Commons Attribution License, which permits unrestricted use, distribution, and reproduction in any medium, provided the original work is properly cited.

\begin{abstract}
Due to its special topographical structure, the forest working environment requires a vehicle chassis that can adapt well to complex terrain conditions. This article describes the key components of a chassis that was designed to adapt to complex terrain. The working principle and structural design of the steering structure and the lifting structure are analyzed in detail, and function verification is carried out. The steering mechanism has three degrees of freedom, and the first degree of freedom reduces the body's inclination by $30^{\circ}$. The second degree of freedom can increase the steering angle of the chassis to $47^{\circ}$, decreasing the turning radius of the chassis. The third degree of freedom reduces the body rollover inclination by $30^{\circ}$. The entire steering mechanism enhances the ride and stability of the chassis. With the lifting mechanism, the wheel-legs are lifted so that the chassis can pass a limit height of $187 \mathrm{~mm}$, and the wheel-legs are lowered to raise the center of gravity of the vehicle chassis by $244 \mathrm{~mm}$. The entire lifting mechanism greatly improves the vehicle's ability to cross forest terrain. The size is reduced by $10 \%$ compared to other structures, and the lifting height and obstacle resistance are improved by $12.7 \%$.
\end{abstract}

\section{Introduction}

Forestry vehicles used to perform forestry tasks such as logging, exploration, harvesting, and transporting logs have limitations. These vehicles must move over the rough terrain of the forest $[1,2]$. However, the biggest challenge for forestry vehicles today is the poor quality of forest roads. Therefore, it is necessary to develop forestry chassis that adapt to complex terrain conditions [3-5]. In the current research stage, forestry vehicles are based on the following two types of chassis: tracked or wheeled [6]. Edlund et al. design a special type of tracked chassis with a new bogie [7]. This chassis has superior cross-country capability compared to common wheeled vehicles, but they also have poor maneuverability, especially poor steering performance. A tracked omnidirectional vehicle was designed by Zhang and Huang [8]. The vehicle has superior steering efficiency and omnidirectional motion ability on uneven terrains. A study of machine design for a transformable shape tracked vehicle system was presented by Kim et al. [9]. Utilization of a variety of shapes provided enhanced ability to surmount obstacles. However, vehicles with a tracked chassis cause major damage to the soil and surrounding plants in the forests. A luffing wheel-leg robot with six legs was introduced by Sun and Liu [10]. This robot can surmount obstacles actively on forest roads. However, this robot has low efficiency for surmounting obstacles. Yao et al. design an innovative all-terrain vehicle with diameter-variable wheels [11]. This vehicle could vary their diameter and overcome higher obstacles compared to standard wheels. But the complicated wheel structure is associated with some risks. Ge and Wang proposed a model of a quadruped eccentric wheel chassis, which achieved excellent performance when crossing obstacles [12]. But vehicle has disappointing driving comfort. In summary, it is particularly significant to design a forest chassis which can overcome the forest problems and 
can operate stably. This chassis must have stable motion smoothness, good vehicle steering function, and efficient crossing obstacles ability.

Generally, mobile robots can be divided into three types: wheeled, crawler, and legged robots [13]. Wheeled robots can move fast and have good stability on flat terrain, but they have difficultly overcoming obstacles on rough terrain. Crawler robots can better navigate obstacles and have better ground adaptability on unstructured ground but have the disadvantage of high energy consumption. Legged robots have the best moving performance on rough terrain, with the disadvantages of slow speed and complicated mechanism and control systems [14-16]. At present, the wheel-leg hybrid mobile robot has become the focus of research because many of the advantages of wheeled and legged robots can be integrated [17-19]. In order to adapt to the complex terrain environment and solve the operation problems in the unstructured environment, the wheel-leg hybrid robot becomes the best solution [20]. There are three situations in wheel-leg robot runs over obstacle. When the double-sided wheels cross the obstacle at the same time, the front and rear end of the frame form a pitch angle. When one side wheel crosses the obstacle, the other side wheel runs smoothly, and the left and right ends of the frame form a rollover angle. When the robot climbs the slope, the frame will form a tilt angle $[21,22]$. The wheel-leg structure can complete the three types of obstacle crossing, and the frame always runs horizontally. The wheel-leg robot has good road profile and ability to cross obstacles [23, 24].

Key components of the FC-3DOF\&LW include a threedegree-of-freedom (3DOFS) articulated structure and a wheel-leg lifting structure (WLLS) [25]. The 3DOFS structure is used for the parallel connection of the front and rear bodies. Due to the particularity of its waist turning, it has better turning radius characteristics than those of the deflection wheel steering [26]. The remaining two degrees of freedom can increase the stability of the deflection from the ground profile as the vehicle crosses an obstacle. The WLLS of the chassis is used to address obstacles; the lifting of the lifting hydraulic cylinder and the countersupporting of the hydraulic cylinder stabilize the chassis plane [27].

This article mainly introduces the design of the mechanical structure and three-degree-of-freedom (3DOFS) forms, determines its functionality, and verifies the function to meet the design criteria. This article also introduces the mechanical structure design of the variable amplitude WLLS. The mathematical model is established, the structural function is analyzed, the obstacle form of the variable amplitude wheel-leg in different working environments is determined, and the function is verified. The studies performed by Zhu et al. introduced a forestry obstacle chassis, and the main obstacle component is the luffing wheel-leg structure $[25,27]$. Compared with its structure, the structure described in this article has improved in performance and function. The hydraulic cylinder structure size is reduced by $10 \%$, and the lifting height is increased by $12.7 \%$. All the active parts have been switched to hydraulic drives. It avoids the complexity of power mixing and improves energy efficiency.

\section{Design of the Structure}

2.1. Concept Design of the Overall Vehicle. In order to surmount rough terrain in the forest, the concept of the vehicle has been designed as Figure 1. It consists of two frames, a 3DOFS and four WLLS. The two frames are connected by an articulated structure with three degrees of freedom. Importantly, the four rear wheel-legs with a lifting function are attached to the rear frame and distributed on both sides symmetrically. In this design, key body structures of the vehicle include 3DOFS and WLLS. Especially, 3DOFS contributes to enhance the capacity to traverse obstacles, and WLLS ensures smooth obstacle surmounting.

2.2. Key Structure Research Methods. After using SolidWorks software for 3D modeling and stress-strain analysis, two key structures have problems. The structures were optimized, and the functions were improved by redesigning the structure and selecting standard components. The specific research method is shown in Figure 2.

2.3. Three-Degree-of-Freedom Structure. Articulated structure is a mechanism which is used in engineering vehicle to make a turn. Due to the rigid design of the traditional articulate structure, the structure is subjected to greater stress during the connection process. It is difficult to adapt to complex terrain in forest. Based on the reason above, articulated structure with three degrees of freedom is shown in Figure 3, which can roll in three directions. This structure is a passive mechanism, which can enhance the capacity to adapt to terrain. When driving in a complex road environment, it ensures full-time contact between wheels and ground.

As shown in Figure 3, the 3DOFS can be divided into three degrees of freedom of a symmetrical structure. The first degree of freedom is composed of a rotating pin and a steering front baffle for controlling the angle of the front frame and the rear frame when rolling over an obstacle. The second degree of freedom consists of a rotating pin, upper and lower covers, and two hydraulic cylinders for controlling the waist turning and the corresponding turning radius. The third degree of freedom consists of a rotating pin and a steering baffle for controlling the angular adjustment between the rear frame and the front frame when rolling over an obstacle.

2.4. Three-Degree-of-Freedom Structure Functionality. The first degree of freedom of the front axle is set to $30^{\circ}$ at the upper limit and 15 degrees at the lower limit. This constraint is used to reduce the inclination angle of the front and rear frames during obstacle crossing and can effectively improve the stability of the rear frame. The second degree of freedom of the central axle sets the deflection angle to $47^{\circ}$, to adjust the turning corner angle. The third degree of freedom of the rear axle sets the left and right limit angles to $30^{\circ}$, to reduce the tilt angle of the front and rear frames when a single side is 


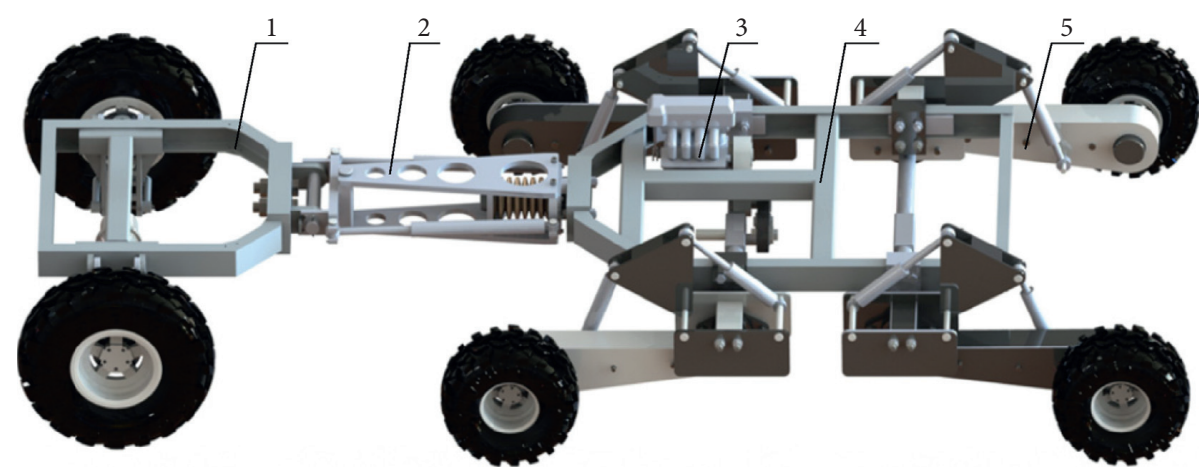

Figure 1: Structure of the overall vehicle. 1, front frame; 2, three-degree-of-freedom structure (3DOFS); 3, power train; 4, rear frame; 5, wheel-leg lifting structure (WLLS).
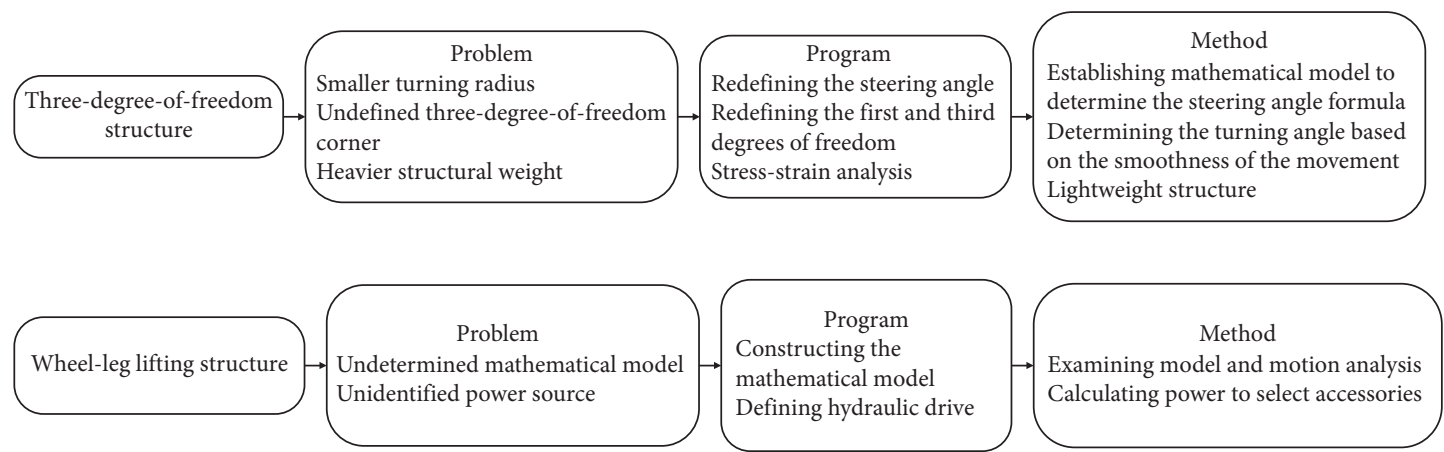

Figure 2: Key structure research workflow.

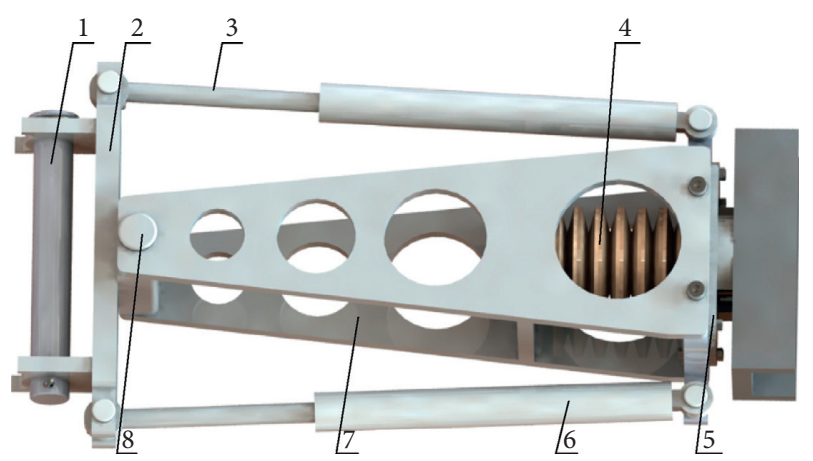

FIGURE 3: The three-degree-of-freedom structure. 1, first-degreeof-freedom pin; 2, steering front baffle; 3 , steering hydraulic cylinder R; 4, third-degree-of-freedom pin; 5 , steering rear baffle; 6 , steering hydraulic cylinder L; 7, upper and lower covers; 8, seconddegree-of-freedom pin.

over obstacle, thereby effectively improving the smoothness of the front frame.

2.5. Wheel-Leg Lifting Structure. The variable amplitude wheel-legs are active devices that control movement by the upper and lower hydraulic cylinders and can realize two working modes. It can be known from Figure 4 that when the lifting hydraulic cylinder is shortened, the wheel-legs are raised, and when the lowering hydraulic cylinder is extended, the wheel-legs are lowered or the chassis height is raised. With this uncoupled motion, it is more convenient to control the wheel position to enhance the chassis driving ability [28-30].

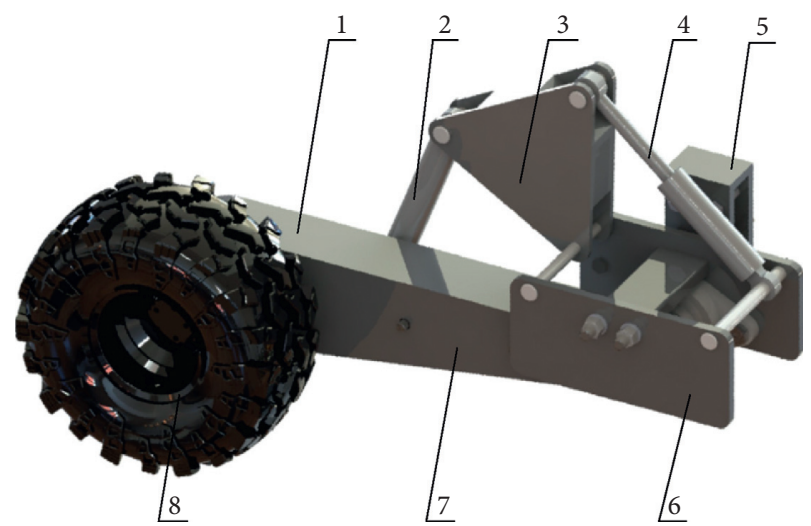

Figure 4: Structure of the wheel-leg lifting. 1, swing arm baffle; 2, lowering hydraulic cylinder; 3, triangle turntable; 4 , lifting hydraulic cylinder; 5 , fixed structure; 6 , connection structure; 7 , swing arm baffle case; 8 , tire.

\section{Motion Analysis}

3.1. Turning Radius Design. Considering the actual working environment and size of the chassis, the intermediate hinged connection uses a folding waist. Waist turning has the advantages of a small turning radius, smooth movement, and simple operation. Compared with traditional deflection wheel steering, the structure is simple, and the turning radius is small [31-33].

As shown in Figures 5 and 6, the vehicle model consists of an independently designed chassis size. $M_{1}$ is the distance 


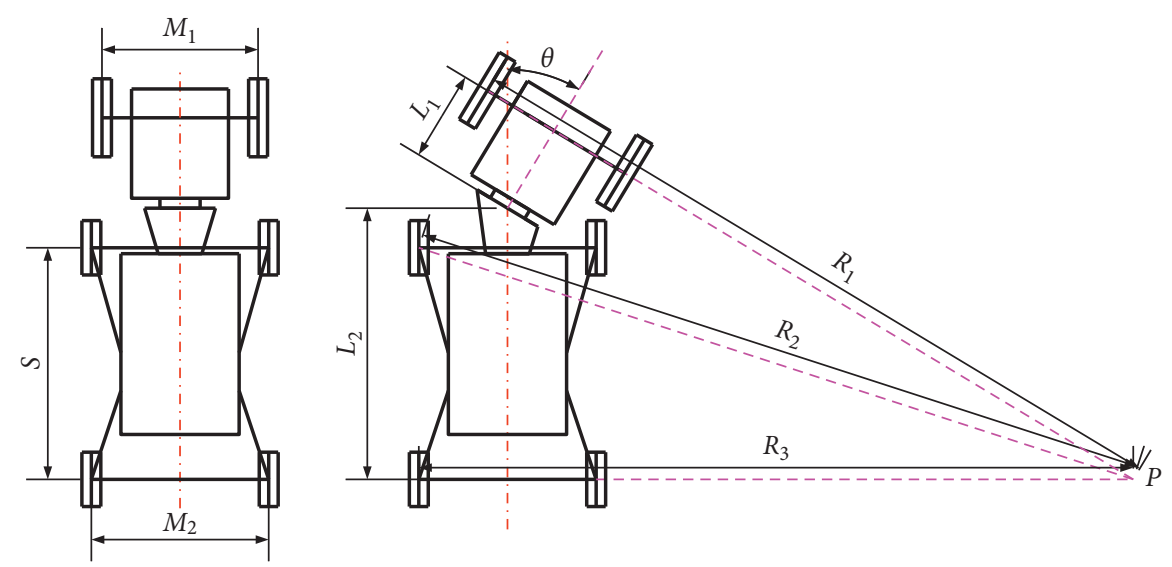

FIGURE 5: Sketch of waist steering radius.
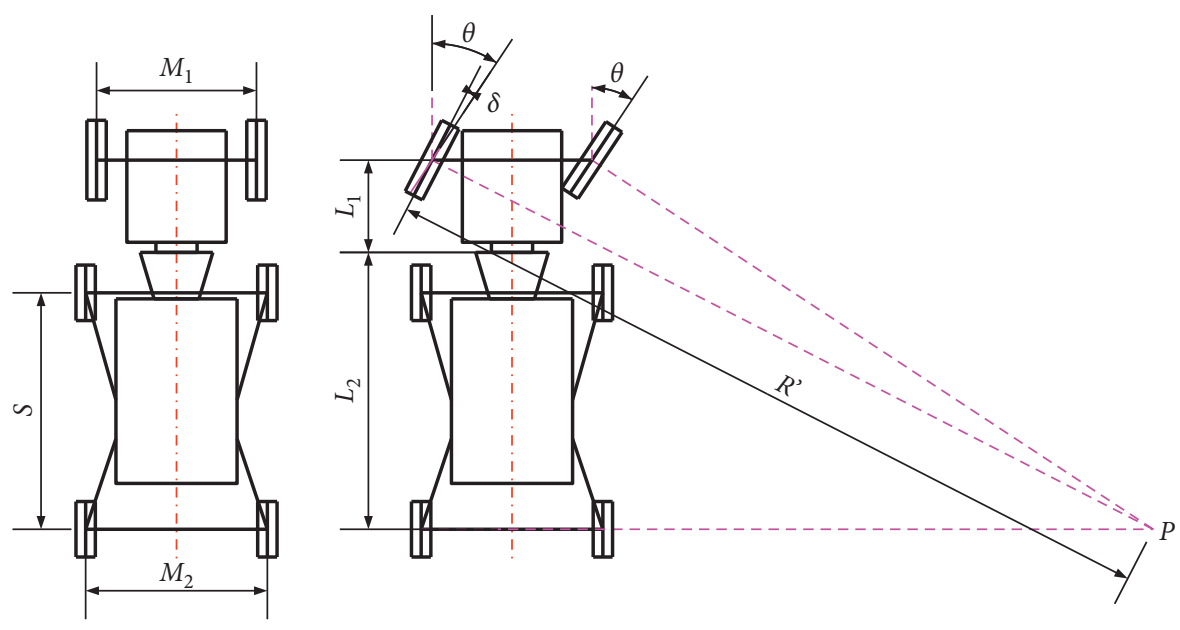

Figure 6: Sketch of single-axis steering radius.

between the front wheels. $M_{2}$ is the distance between the rear wheels. $S$ is the distance between the front and rear wheels of the rear frame. $L_{1}$ is the distance between the hinge point and the front wheel axle. $L_{2}$ is the distance between the hinge point and the rear wheel axle. $\theta$ is the steering angle. $\delta$ means the deflection angle between two wheels. The turning radius of each wheel is as follows:

$$
R_{1}=\frac{M_{1}}{2}+\frac{L_{1}}{\sin \theta \cos \theta}+\frac{L_{2}}{\sin \theta}-L_{1} \tan \theta .
$$

$R_{1}$ represents the turning radius of the front wheel:

$$
R_{3}=\frac{M_{2}}{2}+\frac{L_{1}}{\sin \theta}+\frac{L_{2}}{\tan \theta} .
$$

$R_{3}$ represents the turning radius of the rear wheel:

$$
R_{2}=\sqrt{R_{3}^{2}+S^{2}}
$$

$R_{2}$ represents the turning radius of the middle wheel.

$R^{\prime}$, ordinary three-axle car single-axis steering radius, is as follows:

$$
R^{\prime}=\frac{\left(L_{1}+L_{2}\right)+\left(S^{2} / 4\left(L_{1}+L_{2}\right)\right)}{\sin (\theta-\delta)} .
$$

According to the data in Table 1, the waist turning radius and the normal deflection wheel steering radius are calculated. A data comparison showed that the waist turning radius can be reduced by $15 \%$. The formula for calculating the steering radius in the waist turning radius is a monotonically decreasing function. Therefore, as the turning angle of the waist is further increased, the turning radius of the waist will be further reduced, and the obstacle passing performance will improve. In addition, the steering angle of the waist steering can continue to increase within the range allowed by the structural conditions.

In the concept design of the whole vehicle, the 3DOFS is responsible for adjusting the turning radius. Within the range allowed by the structural conditions, the larger steering angle makes the smaller steering radius. Steering angle adjustment is controlled by a hydraulic cylinder. Steering angle adjustment is controlled by a hydraulic cylinder. Therefore, the hydraulic cylinder with a suitable structural size is selected to make the steering radius not less than $45^{\circ}$.

As shown in Figure 7, $L_{a}$ indicates the length of the steering front baffle, $L_{b}$ represents the length of the steering rear baffle, $L_{c}$ means the length of the upper and lower covers, and $\mathrm{D}_{1}$ is the diameter of the second-degree-offreedom pin. By selecting the stroke of the hydraulic cylinder 
TABLE 1: Initial parameters of the chassis.

\begin{tabular}{lcc}
\hline Parameter & Unit & Value \\
\hline$M_{1}$ & $\mathrm{~mm}$ & 660 \\
$M_{2}$ & $\mathrm{~mm}$ & 750 \\
$S$ & $\mathrm{~mm}$ & 1960 \\
$L_{1}$ & $\mathrm{~mm}$ & 765 \\
$L_{2}$ & $\mathrm{~mm}$ & 2295 \\
$\theta$ & $\circ$ & 45 \\
$\delta$ & $\circ$ & 5 \\
\hline
\end{tabular}

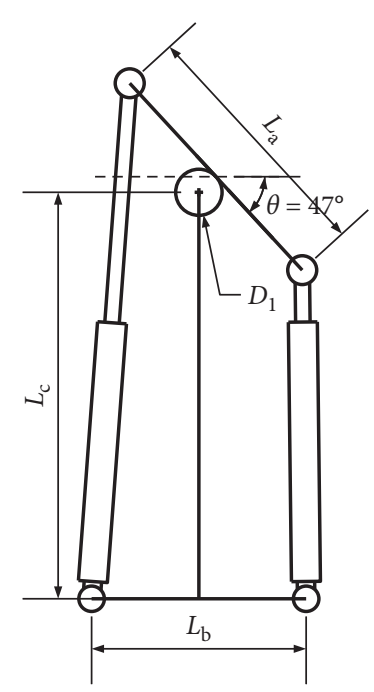

(a)

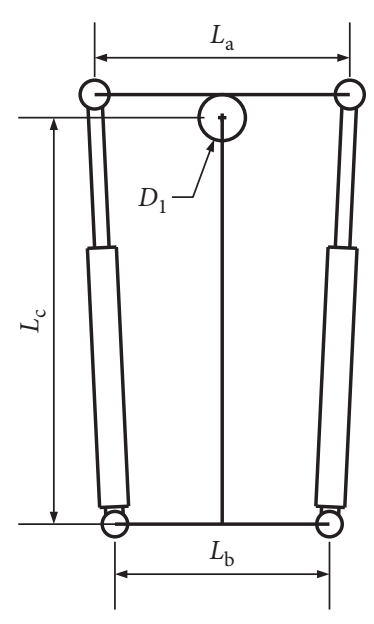

(b)

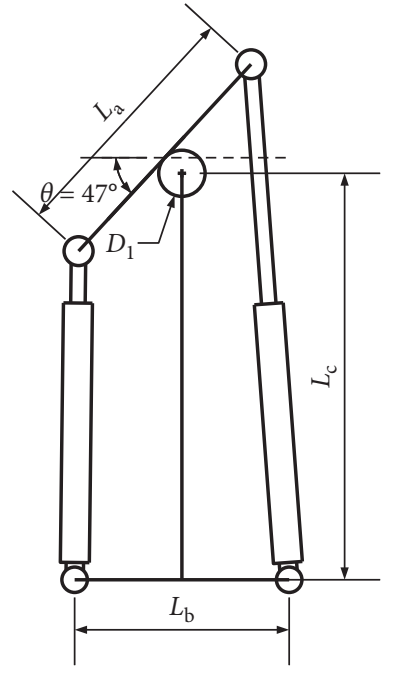

(c)

FIGURE 7: Sketch of the three-degree-of-freedom structure: (a) right limit corner position; (b) normal position; (c) left limit corner position.

$350 \mathrm{~mm}$, the hydraulic cylinder length varies between 570 and $920 \mathrm{~mm}$. When the hydraulic cylinder at one end contracts to the shortest position, the maximum steering angle is reached. By analyzing the sketch of the 3DOFS in AUTOCAD software, it is found that the steering angle $\theta$ reaches $47^{\circ}$, which is greater than $45^{\circ}$, and the steering radius will be further reduced.

3.2. Wheel-Leg Motion Analysis. To analyze the basic motion of the variable amplitude wheel-legs, a simple mathematical model of the variable amplitude wheel-legs is needed. Two forms of motion of the wheel-leg, lifting and falling, are shown as Figures 8 and 9. The lifting height and the falling height of the leg are calculated by simplifying the model.

As shown in Figures 8 and 9, due to the uncoupled movement of the lifting hydraulic cylinder and the descending hydraulic cylinder, during the lifting process, the lifting hydraulic cylinder is extended, the length of the descending hydraulic cylinder is constant, and wheel-leg lifting is realized. During the descent process, the descending hydraulic cylinder is extended, the length of the lifting hydraulic cylinder is constant, and the wheel-leg is lowered or the center of gravity of the chassis is raised. According to the plan model in the figure, the amount of displacement of the wheel-leg in the vertical direction can be calculated.

During the lifting process, the centroid displacement of the wheel-leg is as follows:

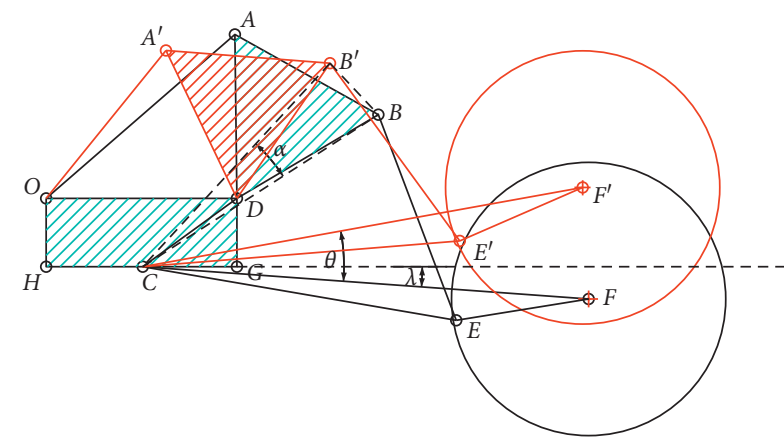

FIgURE 8: Sketch of wheel-leg lifting.

$$
\begin{aligned}
\angle A D O & =\arccos \frac{L_{A D}^{2}+L_{O D}^{2}-L_{O A}^{2}}{2 \times L_{A D} \times L_{O D}}, \\
\angle A^{\prime} D O & =\arccos \frac{L_{A^{\prime} D}^{2}+L_{O D}^{2}-L_{O A^{\prime}}^{2}}{2 \times L_{A^{\prime} D} \times L_{O D}}, \\
\angle B D C & =360^{\circ}-\angle O D C-\angle A D B-\angle A D O, \\
\angle B^{\prime} D C & =360^{\circ}-\angle O D C-\angle A^{\prime} D B^{\prime}-\angle A^{\prime} D O, \\
L_{B C}^{2} & =L_{C D}^{2}+L_{B D}^{2}-2 \times L_{C D} \times L_{B D} \times \cos \angle B D C, \\
L_{B^{\prime} C}^{2} & =L_{C D}^{2}+L_{B^{\prime} D}^{2}-2 \times L_{C D} \times L_{B^{\prime} D} \times \cos \angle B^{\prime} D C .
\end{aligned}
$$




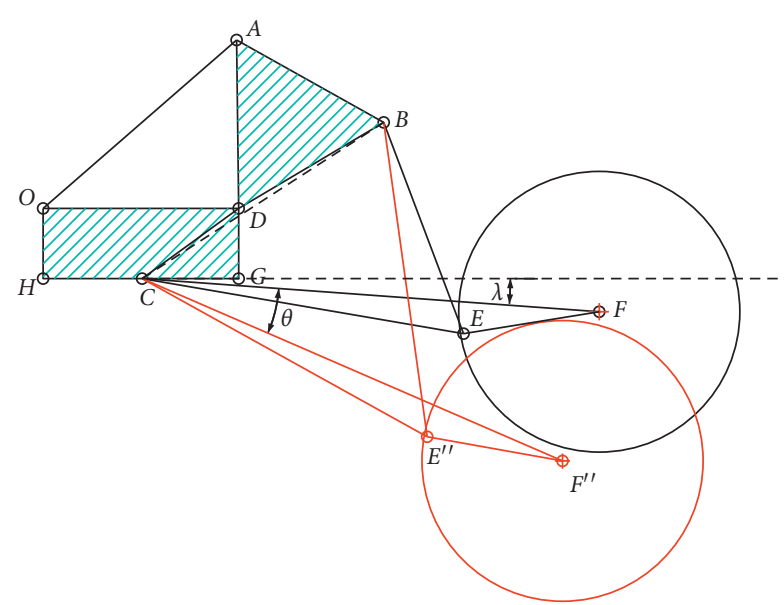

FIGURE 9: Sketch of wheel-leg dropping.

It can be seen from the above conditions that $\triangle B C E, \triangle B^{\prime} C E^{\prime}, \triangle B C D$, and $\triangle B^{\prime} C D$ are fully solved. Thus, the following results are available:

$$
\begin{aligned}
\angle B C E & =\arccos \frac{L_{B C}^{2}+L_{C E}^{2}-L_{B E}^{2}}{2 \times L_{B C} \times L_{C E}}, \\
\angle B^{\prime} C E^{\prime} & =\arccos \frac{L_{B^{\prime} C}^{2}+L_{C E^{\prime}}^{2}-L_{B^{\prime} E^{\prime}}^{2}}{2 \times L_{B^{\prime} C} \times L_{C E^{\prime}}}, \\
\angle B C D & =\arccos \frac{L_{B C}^{2}+L_{C D}^{2}-L_{B D}^{2}}{2 \times L_{B C} \times L_{C D}}, \\
\angle B^{\prime} C D & =\arccos \frac{L_{B^{\prime} C}^{2}+L_{C D}^{2}-L_{B^{\prime} D}^{2}}{2 \times L_{B^{\prime} C} \times L_{C D}}, \\
\alpha & =\angle B C D+\angle B^{\prime} C D, \\
\theta & =\angle B C E-\angle B^{\prime} C E^{\prime}+\alpha .
\end{aligned}
$$

The vertical distance between $F$ and $F^{\prime \prime} H_{F F^{\prime} \perp}$ can be expressed as

$$
H_{F F^{\prime} \perp}=L_{C F^{\prime}} \sin (\theta-\lambda)+L_{C F} \sin \lambda .
$$

During the dropping process, the centroid displacement of the wheel-leg is as follows:

$$
\begin{aligned}
\angle A D O & =\arccos \frac{L_{A D}^{2}+L_{O D}^{2}-L_{O A}^{2}}{2 \times L_{A D} \times L_{O D}}, \\
\angle B D C & =360^{\circ}-\angle O D C-\angle A D B-\angle A D O, \\
L_{B C}^{2} & =L_{C D}^{2}+L_{B D}^{2}-2 \times L_{C D} \times L_{B D} \times \cos \angle B D C .
\end{aligned}
$$

It can be seen from the above conditions that $\triangle B C E$ and $\triangle B C E^{\prime}$ are fully solved. Thus, the following results are available:

$$
\begin{aligned}
\angle B C E & =\arccos \frac{L_{B C}^{2}+L_{C E}^{2}-L_{B E}^{2}}{2 \times L_{B C} \times L_{C E}}, \\
\angle B C E^{\prime \prime} & =\arccos \frac{L_{B C}^{2}+L_{C E^{\prime \prime}}^{2}-L_{B E^{\prime \prime}}^{2}}{2 \times L_{B C} \times L_{C E^{\prime \prime}}}, \\
\theta & =\angle B C E^{\prime \prime}-\angle B C E .
\end{aligned}
$$

The vertical distance between $F$ and $F^{\prime \prime} H_{F F^{\prime \prime}}$ can be expressed as

$$
H_{F F^{\prime \prime} \perp}=L_{C F^{\prime \prime}} \sin (\theta+\lambda)-L_{C F} \sin \lambda .
$$

The component dimensions are measured based on the model data established in SolidWorks. The known data in the motion diagram are shown in Table 2.

According to the above formula and the data in the table, the rising height of the WLLS during the lifting process and the descending height during the descending process can be calculated. Due to the uncoupled movement of the hydraulic cylinder in the WLLS, the lifting hydraulic cylinder works during the lifting process, and the length of the descending hydraulic cylinder does not change. During the descent process, only the descending hydraulic cylinder works, and the length of the lift hydraulic cylinder does not change. Therefore, the vertical displacement of the centroid of the wheel-leg during lifting is $187.6 \mathrm{~mm}$, and the vertical displacement of the centroid of the wheel-leg is $244.4 \mathrm{~mm}$ during the descending process.

3.3. Climbing Strategy. According to the above analysis, the range of variation in the wheel-leg can be obtained. When the end of the wheel-leg is raised to the highest position and the end is extended to the longest position, the plane inclination of the working platform is reduced. This dip angle reduction will benefit the working platform during the climbing process and enhance the smoothness of the platform during the climbing process [27].

As shown in Figure 10, the WLLS is attached to the test bench. The test bench is a simple frame formed by aluminum profiles. The height of the frame is consistent with the natural droop height of the WLLS. The structure shown in the figure is used for analysis of the climbing motion. When the end of the wheel-leg is raised to the highest position and the end is extended to the longest position, by calculating the data, the slope inclination can be reduced by $12.08^{\circ}$. The reduced angle of inclination helps the work platform to remain stable while climbing. This means that the slope of the platform inclination will reduce $12.08^{\circ}$ when the chassis equipped with the WLLS is used for climbing work. When climbing a slope within $12.08^{\circ}$, the platform can always be level on the level, ensuring stable platform climbing.

\section{Establishment of the Simulation}

To verify the validity and functionality of the 3DOFS and the WLLS, a virtual prototype of the corresponding structure was established in SolidWorks, simulation was carried out in 
TABLE 2: Initial parameters of the luffing wheel-leg.

\begin{tabular}{lcc}
\hline Parameter & Unit & Value \\
\hline$L_{O A}$ & $\mathrm{Mm}$ & 420 \\
$L_{O A^{\prime}}$ & $\mathrm{Mm}$ & 320 \\
$L_{B E}=L_{\mathrm{B}^{\prime} \mathrm{E}^{\prime}}$ & $\mathrm{Mm}$ & 370 \\
$L_{B E^{\prime \prime}}$ & $\mathrm{Mm}$ & 520 \\
$L_{O D}$ & $\mathrm{Mm}$ & 320 \\
$L_{A D}=L_{B D}=L_{A^{\prime} D}=L_{B^{\prime} D}$ & $\mathrm{Mm}$ & 276 \\
$L_{C D}$ & $\mathrm{Mm}$ & $115 / \cos 54^{\circ}$ \\
$L_{C E}=L_{C E^{\prime}}$ & $\mathrm{Mm}$ & 534 \\
$L_{C F}=L_{C F^{\prime}}=L_{C F^{\prime \prime}}$ & $\mathrm{Mm}$ & 750 \\
$\angle O D C$ & $\circ$ & $36^{\circ}$ \\
$\angle C D G$ & $\circ$ & $54^{\circ}$ \\
$\lambda$ & $\circ$ & $4.15^{\circ}$ \\
\hline
\end{tabular}

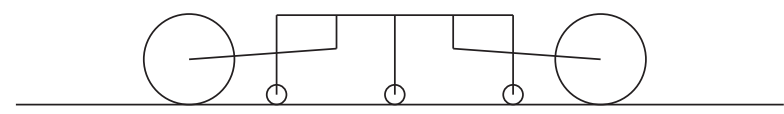

(a)

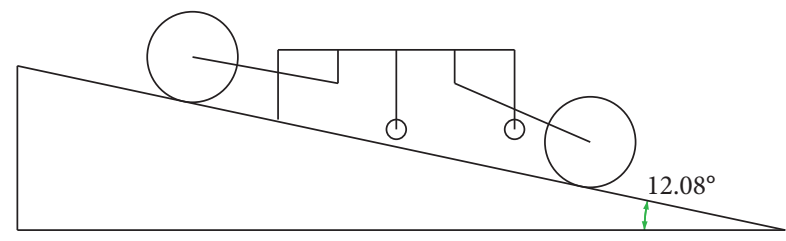

(b)

FIGURE 10: Sketch of climbing: (a) normal walking; (b) climbing process.

ADAMS, and the corresponding multibody dynamics analysis was constructed $[34,35]$.

The simulation process mainly includes the single-degree-of-freedom motion, two-two mixed motion, and threedegree-of-freedom motion (3DOFS) of the lifting height, the inclination of the climbing slope, the double-wheel obstacle, and the one-sided obstacle of the WLLS.

4.1. Mechanical Analysis during Structure Operation. During the operation of the 3DOFS, the structural force analysis by ANSYS is shown in Figure 11. The force $A$ represents natural gravity. Torque $B$ means the torque experienced by the first pin, mainly from the torque generated by the gravity of the front frame. Torque $C$ is the torque experienced by the second pin, mainly from the torque under the action of the hydraulic cylinder. Torque $D$ is the torque received by the third pin, mainly from the torque formed by the rear frame's deflection due to gravity. Forces $E$ and $\mathrm{F}$ are the pulling and pushing forces provided by the hydraulic cylinder. Under the effect of all the above forces, the 3DOFS completes the deflection in three directions of freedom.

The WLLS force analysis by ANSYS is shown in Figure 12. The force $A$ represents natural gravity. Force $G$ means the pulling force provided by the lowering hydraulic cylinder. Force $H$ is the pulling force provided by the lifting cylinder. Force $I$ is the supporting reaction force provided by the frame. Torque $J$ is the torque provided by

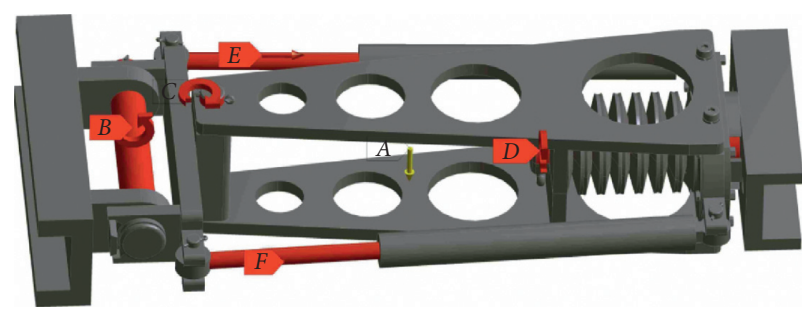

FIGURE 11: Force analysis during the three-degree-of-freedom structure operation.

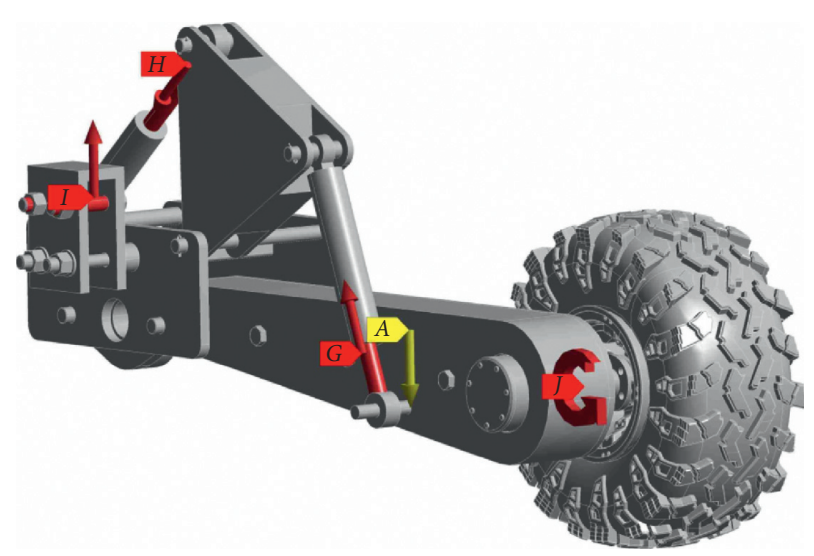

FIgURE 12: Force analysis during the wheel-leg structure operation.

the hydraulic motor. Under the effect of all the above forces, the WLLS completes the movements such as driving and wheel-leg lifting.

4.2. The Simulation of Three-Degree-of-Freedom Structure Motion. The virtual 3D model of the 3DOFS is established in SolidWorks and is imported into ADAMS that is applied in multibody dynamics simulation. In order to verify the motion characteristics of 3DOFS, the motion devices are set to be connected through moving joints and cylindrical joints. The power is driven by the motor to add torque. Set a basic gravity of $9.8 \mathrm{~m} / \mathrm{s}^{2}$. The exercise time is set to $10 \mathrm{~s}$, and the number of steps is set to 500 . The basic parameters are shown in Table 3.

To verify the steering characteristics of the first degree of freedom and to keep the other components fixed, a torque is applied to the first steering shaft. As shown in Figure 13, the blue position represents the position at which the first degree of freedom is stable. The yellow position represents the upper extreme position on the first degree of freedom with a limit angle of $30^{\circ}$. The red position represents the lower limit position at the first degree of freedom with a limit angle of $15^{\circ}$.

In order to verify the steering characteristics of the second degree of freedom and to keep the other components fixed, a force is applied to the steering hydraulic cylinder and a torque is applied to the second steering shaft. It can be known from Figure 14 that the right limit position steering angle is $47^{\circ}$. The left limit position steering angle is also $47^{\circ}$. Steering angle requirements are achieved on both sides. 
TABLE 3: Basic parameters of the three-degree-of-freedom structure in simulation.

\begin{tabular}{lcc}
\hline Parameter & Unit & Value \\
\hline Length & $\mathrm{mm}$ & 1092 \\
Width & $\mathrm{mm}$ & 490 \\
Height & $\mathrm{mm}$ & 230 \\
Mass & $\mathrm{kg}$ & 89 \\
Torque $B$ & $\mathrm{~N} / \mathrm{m}$ & 236 \\
Torque $C$ & $\mathrm{~N} / \mathrm{m}$ & 218 \\
Torque $D$ & $\mathrm{~N} / \mathrm{m}$ & 580 \\
Force $E=$ force $F$ & $\mathrm{~N}$ & 700 \\
\hline
\end{tabular}

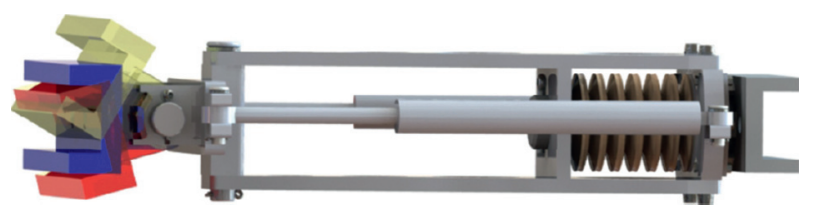

FIgURE 13: Simulation of the first degree of freedom.

To verify the steering characteristics of the third degree of freedom and to keep the other components fixed, a torque is applied to the third steering shaft. As shown in Figure 15, the blue position represents the position at which the third degree of freedom is stable. The yellow position represents the left extreme position on the third degree of freedom with a limit angle of $30^{\circ}$. The red position represents the right limit position at the third degree of freedom with a limit angle of $30^{\circ}$

It is verified that the three-degrees-of-freedom work at the same time and maintain the corresponding working conditions, and the corresponding force is applied. After the dynamic simulation, the 3DOFS can work cooperatively or independently because the degrees of freedom are independent (Figure 16).

4.3. The Simulation of Wheel-Leg Structure Motion. The virtual 3D model of the WLLS is established in SolidWorks. It is imported into ADAMS and applied in multibody dynamics simulation. The basic parameters are shown in Table 4. Tires of chassis are based on the Fiala model, and parameters are shown in Table 5. In simulation process, the initial velocity of WLLS is $2 \mathrm{~m} / \mathrm{s}$. In addition, a $170 \mathrm{~mm}$ obstacle is built in ADAMS. Set a basic gravity of $9.8 \mathrm{~m} / \mathrm{s}^{2}$. The static and rolling friction coefficients are set. According to the relative size, the simulation time is $15 \mathrm{~s}$, and the number of steps is 2000 .

To verify the lifting and lowering functionality of the WLLS, the wheel-legs are fixed on a work platform. The functionality of the WLLS is verified by the lifting and lowering of the hydraulic cylinder. As shown in Figure 17, by applying a displacement of $100 \mathrm{~mm}$ to the lifting cylinder and a displacement of $150 \mathrm{~mm}$ to the descending cylinder, it is verified that the slope inclination decreases $12.3^{\circ}$.

The two-wheeled obstacle form of the WLLS is checked. It can be seen from Figure 18 that the working platform first runs smoothly on the horizontal surface. When the structure is about to collide with the obstacle, the lifting hydraulic cylinder activates, and the WLLS rises and crosses the obstacle. Then, the lifting hydraulic cylinder descends to reach the obstacle height, and the working platform moves on top of the obstacle. When leaving the obstacle, the lifting hydraulic cylinder returns to its original position, the wheellegs fall, the platform continues to run stably, and the twowheeled obstacle crossing process is completed.

The one-sided obstacle pattern is detected. The overall process of the one-sided obstacle pattern of the WLLS can be seen in Figure 19. The working platform runs smoothly on the horizontal surface, and the front WLLS rises when it encounters an obstacle, falls when it crosses the obstacle, and runs stably on the obstacle. After that, the rear wheel-leg rises when encountering an obstacle and falls to the obstacle height when crossing the obstacle, and the two legs simultaneously run stably on the obstacle. Then, as the obstacle is crossed, the front wheel-leg falls to the normal height, and then the rear wheel-leg falls to the normal height. The one-sided obstacle crossing process is completed, and the working platform is stable.

\section{Discussion of the Simulation Results}

The dynamics simulations of the 3DOFS and the WLLS were carried out, and the corresponding results were obtained. The structural functionality was verified. The 3DOFS can realize angular deflection and independent movement in all three directions, and the WLLS can reach the design lifting height and match the theoretical model. Functional verification of critical components is achieved by applying corresponding force and displacement conditions throughout the process.

Figure 20 records the rotation angles of the three-degreeof-freedom structure in three directions while moving simultaneously. It can be seen from the figure that the limit degree of the first-degree-of-freedom motion is $45^{\circ}$, which is consistent with the principle of first-degree-of-freedom design. The second-degree-of-freedom motion angle, that is, the steering radius angle, reaches $47.1^{\circ}$, which is consistent with the theoretical model. The breakpoint in the figure refers to the invalid data point after the hydraulic cylinder reaches the shortest end and is not included in the steering radius. The third-degree-of-freedom motion angle reaches a maximum of $30^{\circ}$ and a minimum of $-30^{\circ}$, which is in line with the third-degree-of-freedom design principle.

The simulation results are obtained by applying a prescribed stroke to the lifting hydraulic cylinder and the descending hydraulic cylinder. Figure 21 shows that when the lifting hydraulic cylinder is working, the lifting height of the WLLS is $187 \mathrm{~mm}$, and when the descending hydraulic cylinder is working, the falling height of the WLLS is $244 \mathrm{~mm}$. The simulation results are consistent with the theoretical model and meet the design requirements.

Figure 22 shows that the reduction in the inclination of the platform slope can be achieved by the lifting of the lifting cylinder and the lowering of the hydraulic cylinder, which can be reduced by $12.3^{\circ}$, which is in accordance with the theoretical model. The reduction in the platform slope allows the chassis to maintain the smoothness of the working 


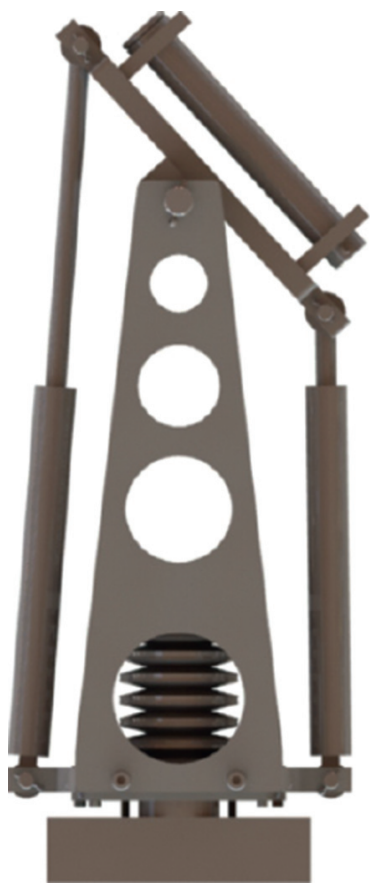

(a)

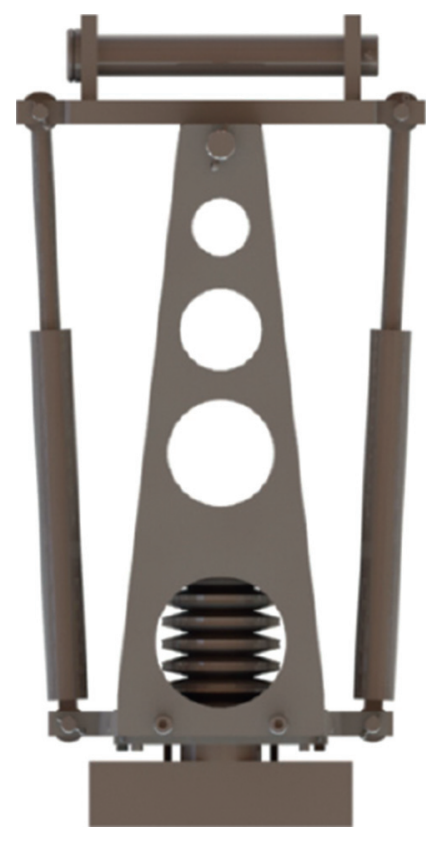

(b)

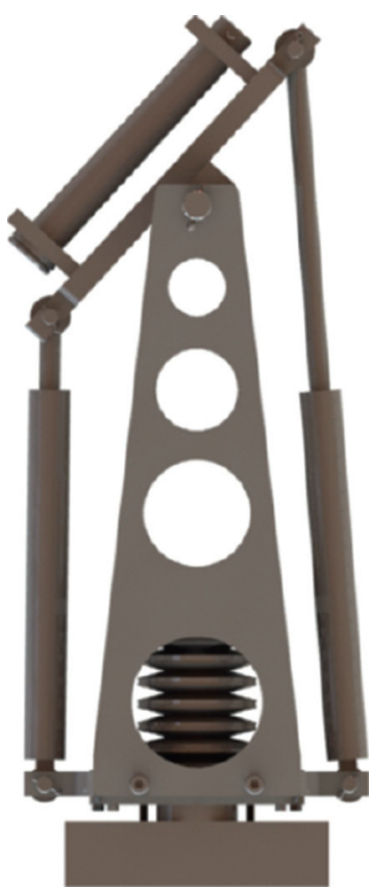

(c)

Figure 14: Simulation of the second degree of freedom: (a) second-degree-of-freedom right limit position; (b) stable state; (c) seconddegree-of-freedom left limit position.

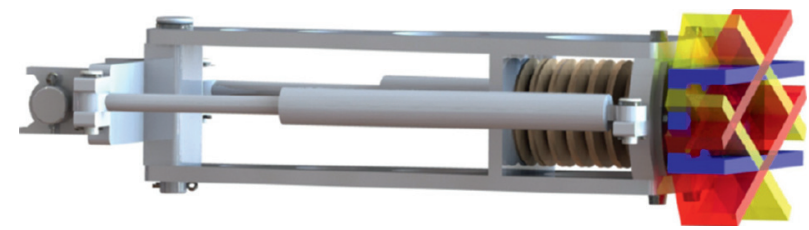

FIgURE 15: Simulation of the third degree of freedom.

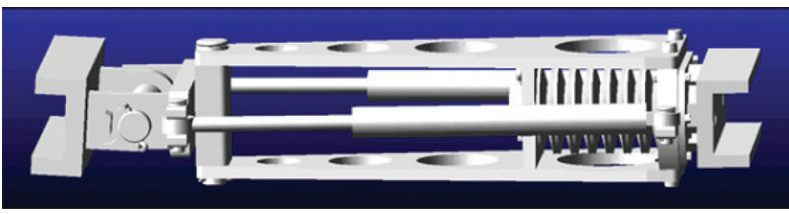

(a)

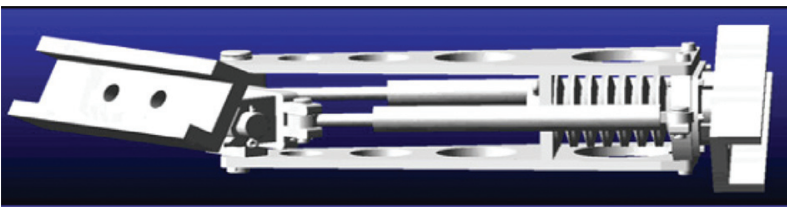

(b)

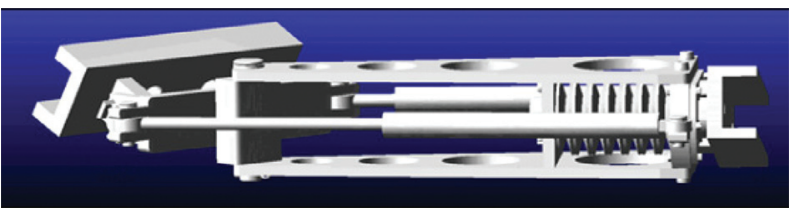

(c)

FiguRE 16: Simulation of the three-degree-of-freedom: (a) stable state; (b) three-degree-of-freedom limit position one; (c) three-degree-offreedom limit position two.

platform within $12.3^{\circ}$ during the climbing process, which is beneficial to the passage of the chassis.

It can be seen from Figure 23 that, during the twowheeled obstacle crossing process, the centroid displacement of the wheel-leg is basically consistent with the data determined in the theoretical model, and the error is within $0.5 \mathrm{~mm}$. The leg-raising process is completed in $1 \mathrm{~s}$ and reaches a maximum height of $187.67 \mathrm{~mm}$, and then the legs fall back to the normal obstacle height of $170 \mathrm{~mm}$ and run stably. When the obstacle crossing process is completed, the 
TABLE 4: Basic parameters of the wheel-leg structure in simulation.

\begin{tabular}{lcc}
\hline Parameter & Unit & Value \\
\hline Length & $\mathrm{mm}$ & 1644 \\
Width & $\mathrm{mm}$ & 1285 \\
Mass & $\mathrm{kg}$ & 246 \\
Engine rated power & $\mathrm{kW}$ & 8.5 \\
Static friction coefficient & & 0.3 \\
Rolling resistance coefficient & & 0.025 \\
Force $G$ & $\mathrm{~N}$ & 352 \\
Force $H$ & $\mathrm{~N}$ & 876 \\
Force $I$ & $\mathrm{~N}$ & 964 \\
Torque $J$ & $\mathrm{~N} / \mathrm{m}$ & 50.4 \\
\hline
\end{tabular}

TABLE 5: Basic parameters of the tires.

\begin{tabular}{lcc}
\hline Parameter & Unit & Value \\
\hline Wheel diameter & $\mathrm{Mm}$ & 357 \\
Wheel width & $\mathrm{Mm}$ & 160 \\
Vertical stiffness & $\mathrm{N} / \mathrm{mm}$ & 310 \\
Vertical damping & $\mathrm{N} /(\mathrm{mm} / \mathrm{s})$ & 3.1 \\
CSLIP & $\mathrm{N} / \mathrm{mm}$ & 1000 \\
CALPHA & $\mathrm{N} / \mathrm{rad}$ & 800 \\
CGAMMA & $\mathrm{N} / \mathrm{mm}$ & 300 \\
\hline
\end{tabular}

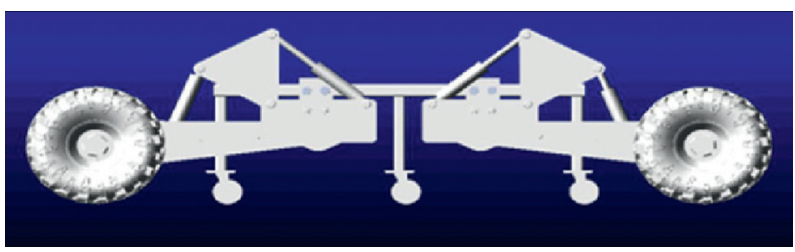

(a)

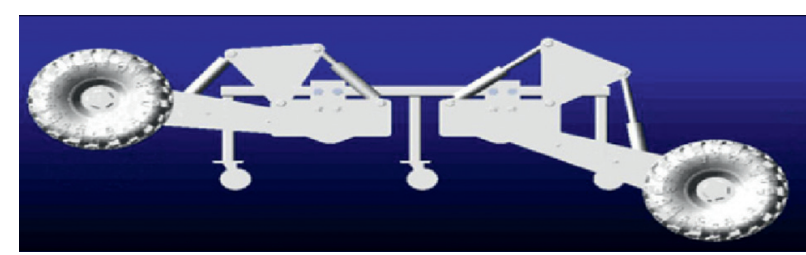

(b)

FIGURE 17: Simulation of the climbing slope process: (a) stable state; (b) wheel-leg structure climbing slope limit inclination position.

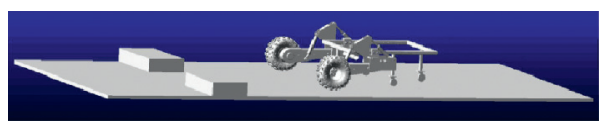

(a)

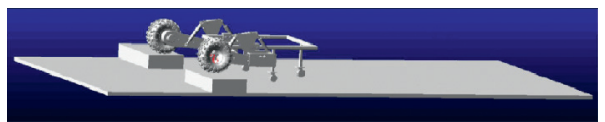

(c)

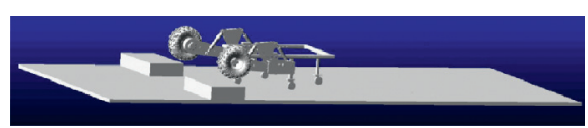

(b)

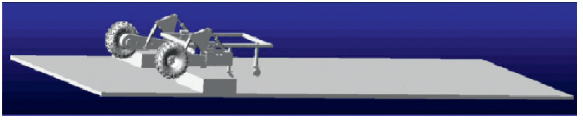

(d)

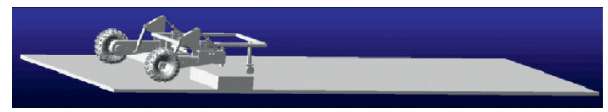

(e)

FIGURE 18: Simulation of two-wheeled obstacle: (a) smooth running during the two-wheeled obstacle; (b) wheel-legs lifting at the twowheeled obstacle; (c) wheel-legs driving on the two-wheeled obstacle; (d) wheel-legs dropping in front of the two-wheeled obstacle; (e) smooth running after the two-wheeled obstacle is passed.

wheel-legs fall back to the initial position, and the lifting and falling process is completed in $1 \mathrm{~s}$. It is proven that the WLLS can use two wheels simultaneously to overcome obstacles of $170 \mathrm{~mm}$.
As shown in Figure 24, the relationship between the motions of the two legs during one-sided obstacle crossing can be determined. The front wheel-legs first rise to a maximum height of $187.67 \mathrm{~mm}$ and then fall back to the 


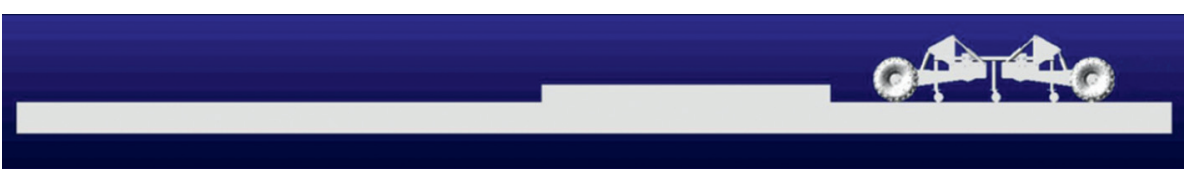

(a)

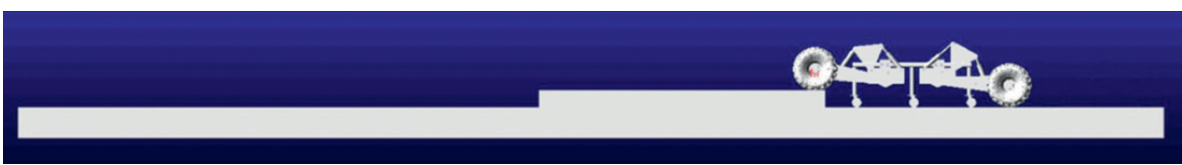

(b)

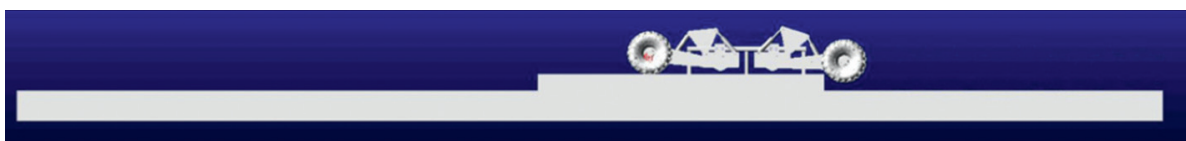

(c)

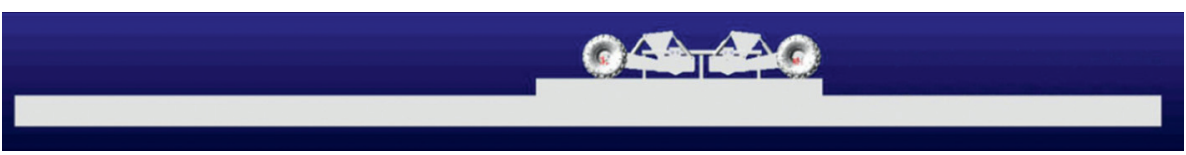

(d)

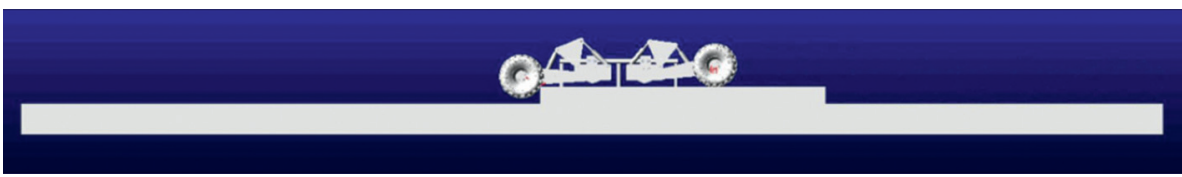

(e)

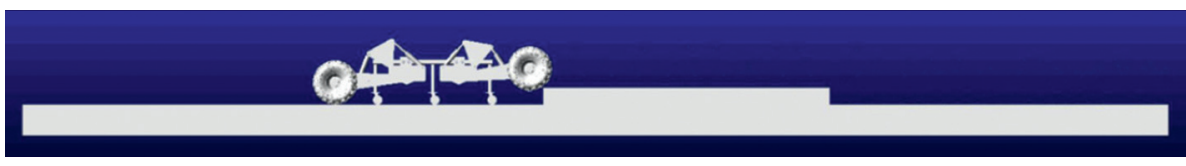

(f)

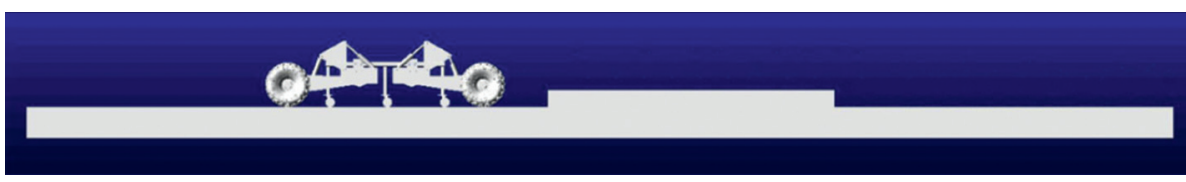

(g)

FIGURE 19: Simulation of one-sided obstacle: (a) smooth running during the one-sided obstacle; (b) front wheel-legs lifting process during the one-sided obstacle; (c) rear wheel-legs lifting process during the one-sided obstacle; (d) wheel-legs driving on the obstacle process during the one-sided obstacle; (e) front wheel-legs dropping process during the one-sided obstacle; (f) rear wheel-legs dropping process during the one-sided obstacle; (g) smooth running after the one-sided obstacle.

obstacle height of $170 \mathrm{~mm}$; the whole process is completed in $1 \mathrm{~s}$. When the rear wheel-legs is over the obstacle, it rises to a maximum height of $187.31 \mathrm{~mm}$ and then falls back to the obstacle height of $170 \mathrm{~mm}$. Due to the error of the installation position of the hydraulic cylinder in the WLLS, the limit position of the two wheel-legs has an error within $0.5 \mathrm{~mm}$. Through verification, the WLLS has the ability to overcome $170 \mathrm{~mm}$ during one-sided obstacle crossing.

\section{Experiments}

To verify the feasibility and functionality of the mechanical structure, the mechanical structure was drawn into CAD drawings to machining. According to the simulation environment, the corresponding experiment process is established:
(1) The 3DOFS is shown in Figure 25. This structure is placed on the ground and powered by a hydraulic station to verify the steering performance. Through the movement of the hydraulic cylinders, when the length of the left hydraulic cylinder reaches $570 \mathrm{~mm}$, the steering angle to the left reaches the maximum in the left turn process. The steering angle to the right reaches the maximum when the length of the right hydraulic cylinder reaches $570 \mathrm{~mm}$. After several movements and measuring, the maximum steering angles at both ends were $47^{\circ}$.

(2) The two-wheeled obstacle process of the WLLS is shown in Figure 26. The WLLS was fixed to both ends of the designed test platform. Set the rotation speed of the hydraulic motor to $200 \mathrm{rpm}$. The lifting 


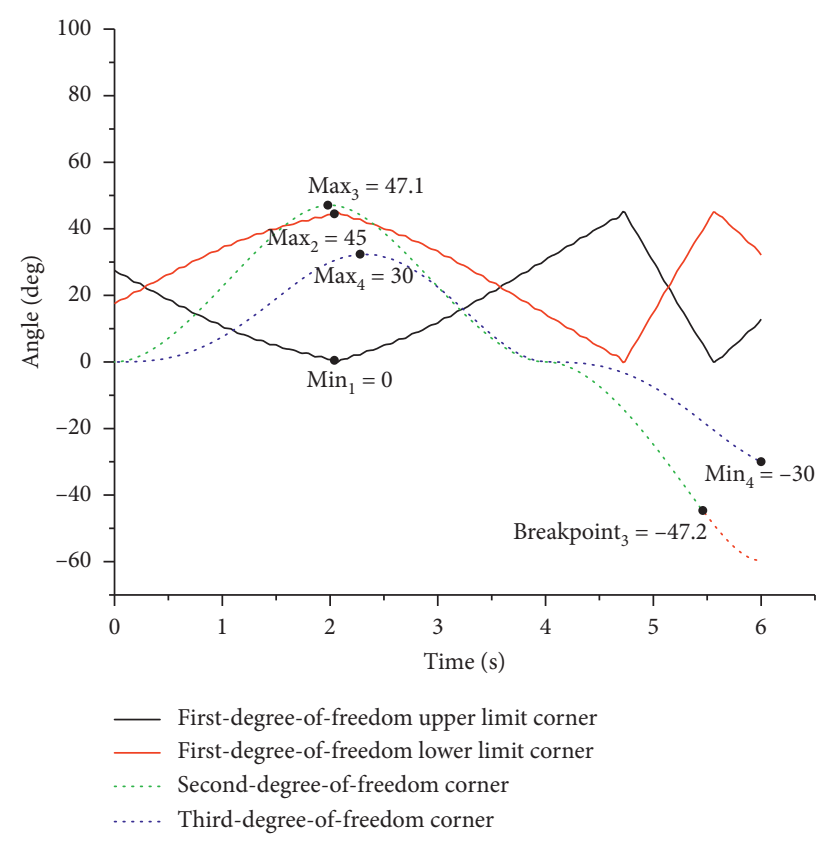

Figure 20: Three-degree-of-freedom rotation angle.

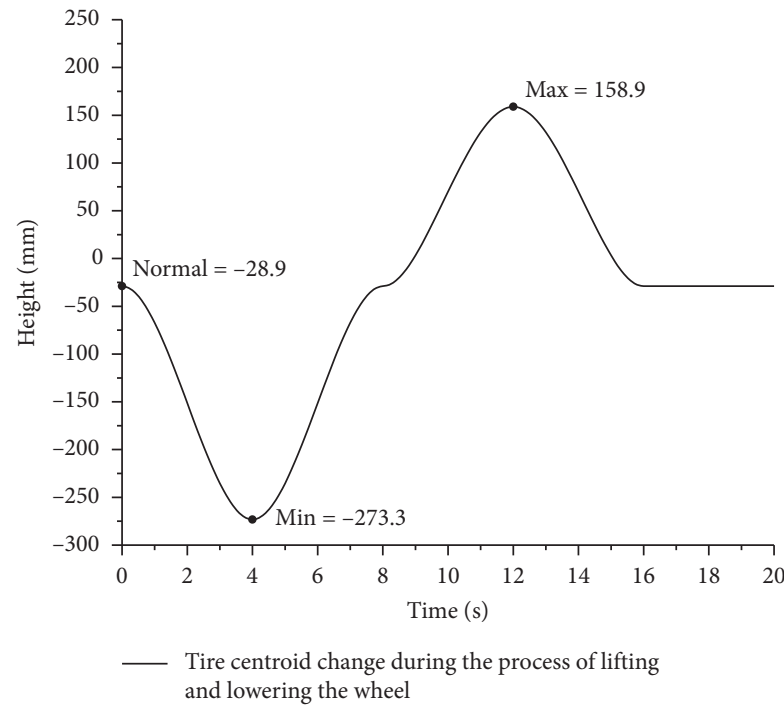

Figure 21: Centroid lifting height change during wheel-leg structure motion.

of four hydraulic cylinders and the rotation speed of two hydraulic motors are controlled by a six-way servo valve. Set the test two-wheeled obstacle height to $170 \mathrm{~mm}$. The verification through the test process is consistent with the simulation process. The WLLS can well overcome the $170 \mathrm{~mm}$ two-wheeled obstacle. By adjusting the stroke of the hydraulic cylinder, it can further overcome the higher obstacle.

(3) As shown in Figure 27, the WLLS was fixed to one side of the designed test platform. To balance the

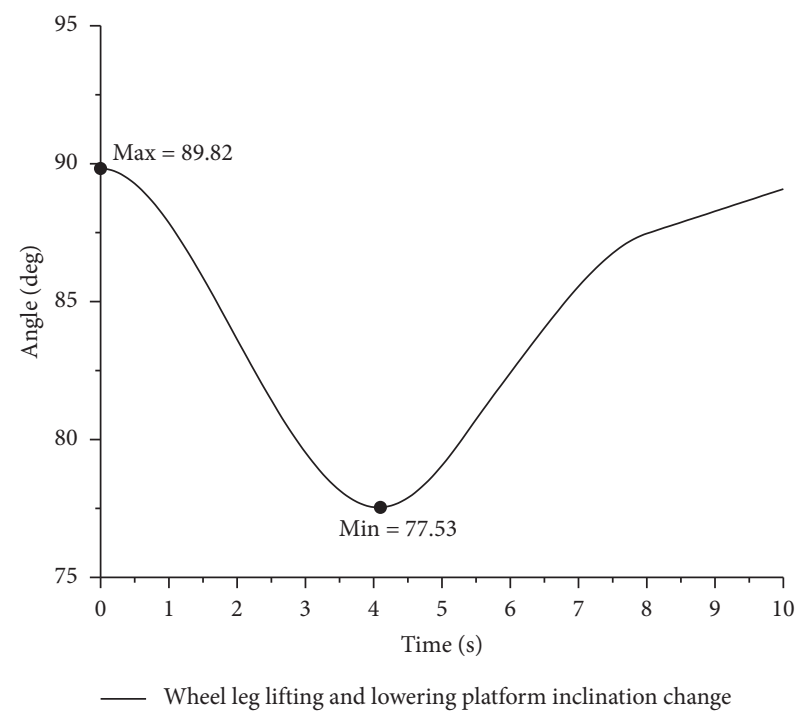

FIGURE 22: Platform inclination change during wheel-leg structure motion.

weight, a weight block was added on the other side of the test platform. During operation, the weight block can ensure the stability of the test platform and prevent it from tipping over. Also, set the hydraulic motor rotation speed to $200 \mathrm{rpm}$. Set the test onesided obstacle height to $170 \mathrm{~mm}$. Power is provided by a hydraulic station to move the overall frame. The verification through the test process is consistent with the simulation process. The WLLS can well overcome the $170 \mathrm{~mm}$ one-sided obstacle.

Through the actual verification of the simulation process, the 3DOFS and WLLS can realize the functions of steering 


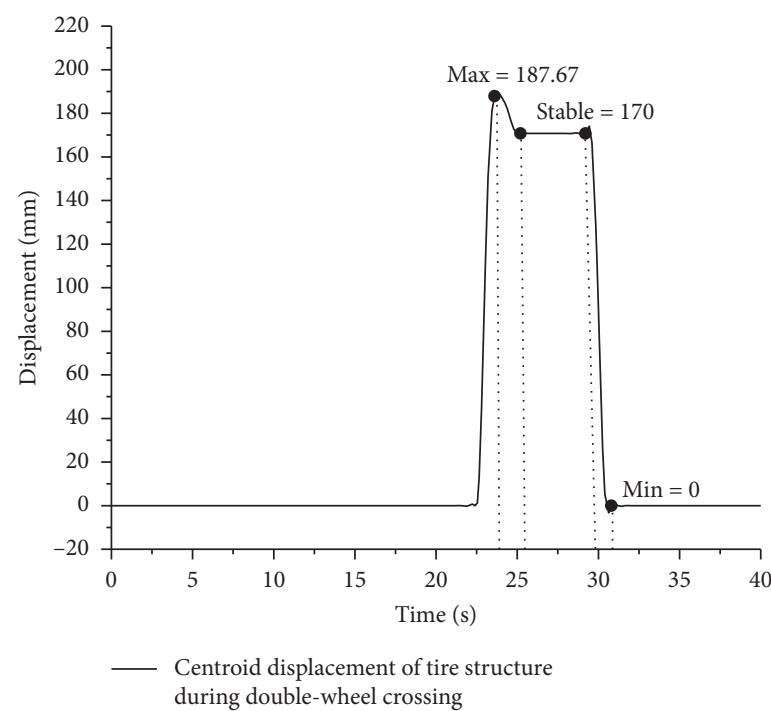

FIGURE 23: Displacement diagram of tire structure centroid during double-wheel crossing.

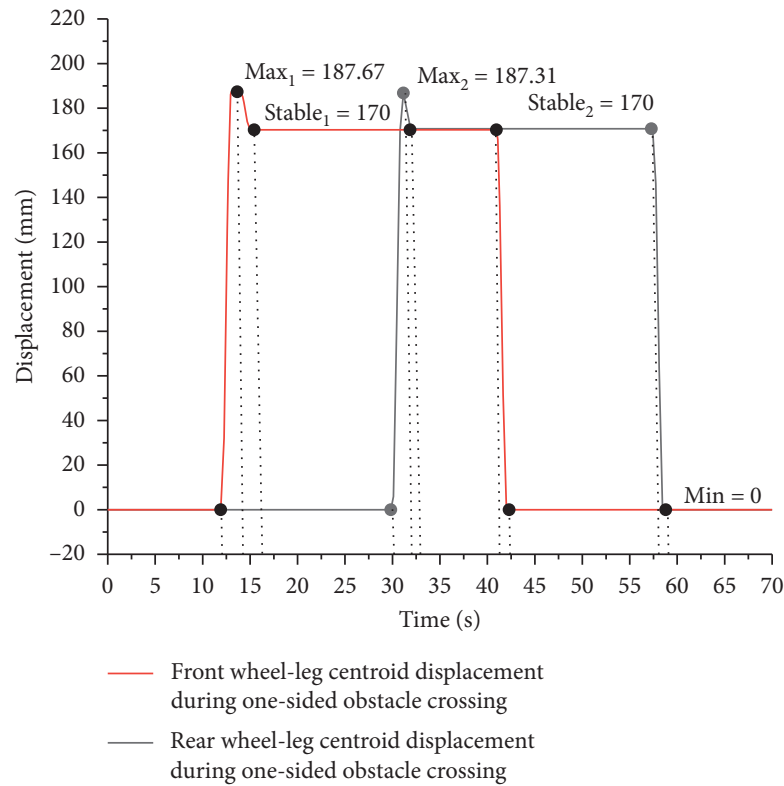

FiguRE 24: Displacement diagram of tire structure centroid during one-sided obstacle crossing.

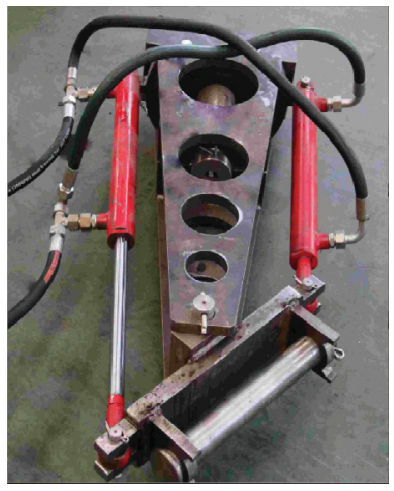

(a)

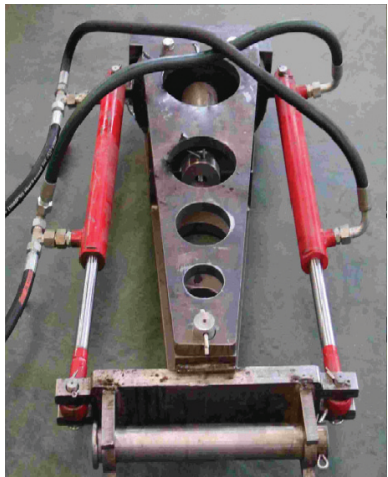

(b)

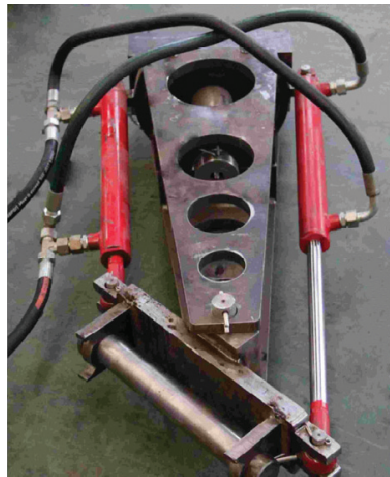

(c)

FIGURE 25: Steering performance of the three-degree-of-freedom structure: (a) left limit corner position; (b) normal position; (c) right limit corner position. 


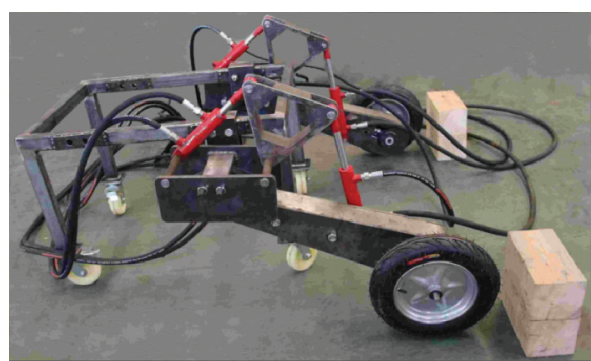

(a)

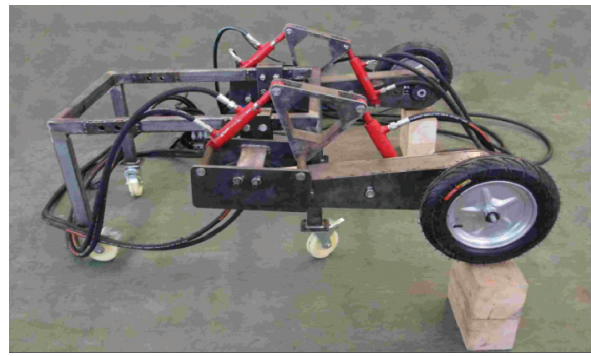

(c)

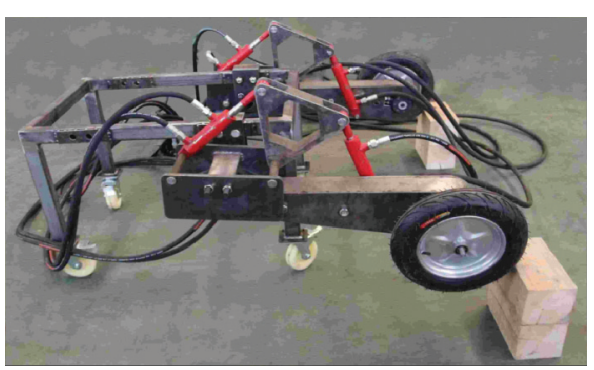

(b)

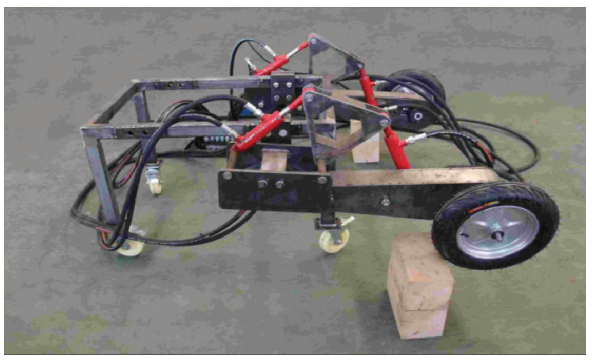

(d)

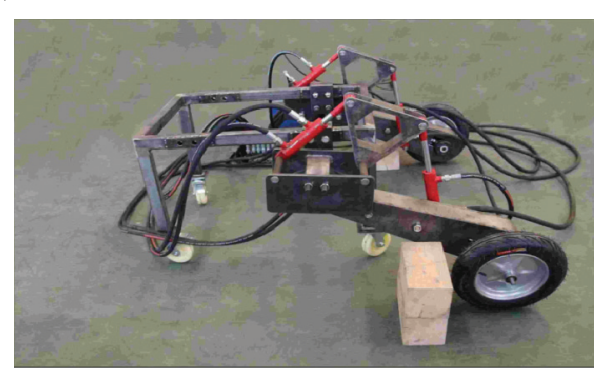

(e)

FiguRE 26: Obstacle crossing performance of two-wheeled obstacle: (a) normal driving; (b) wheel-legs lifting process; (c) wheel-legs driving on the two-wheeled obstacle; (d) wheel-legs dropping process; (e) smooth driving after the obstacle.

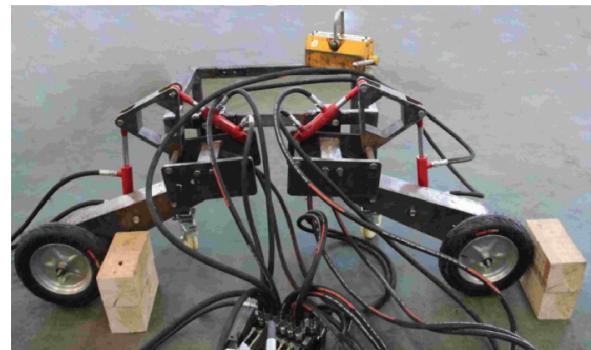

(a)

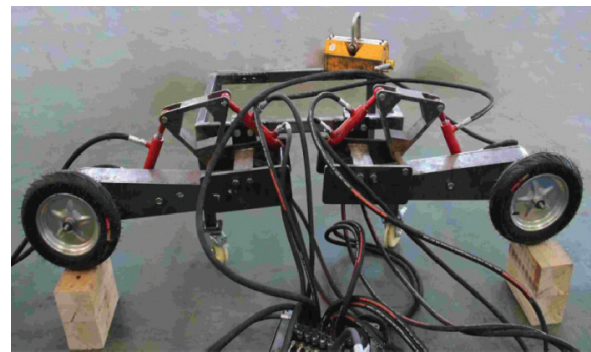

(c)

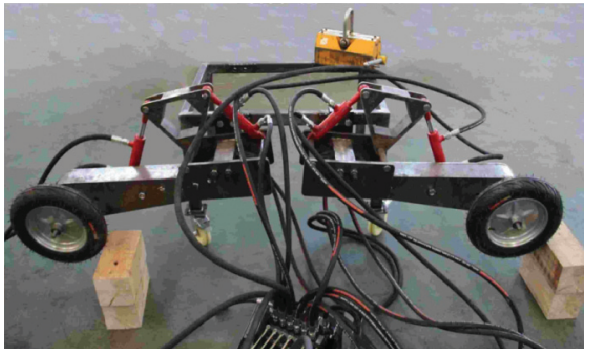

(b)

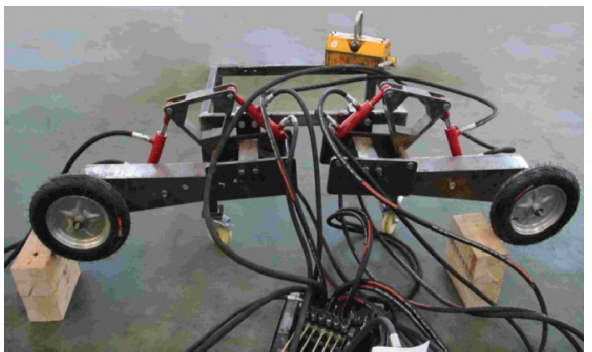

(d)

FIgURe 27: Continued. 


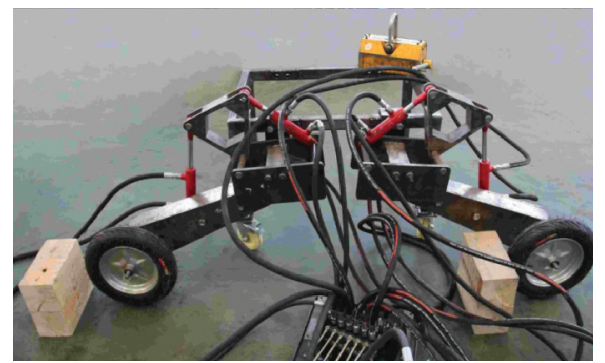

(e)

FiguRE 27: Obstacle crossing performance of one-sided obstacle: (a) smooth running; (b) wheel-legs lifting process; (c) wheel-legs driving on the obstacle; (d) wheel-legs dropping process; (e) normal driving after obstacle.

and obstacle crossing. The experimental results show that the key components can achieve stable motion, which proves the feasibility of the design.

\section{Conclusion}

(1) The steering and lifting mechanism of a forestry vehicle chassis was designed, and the size, structure, and steering radius of the 3DOFS were determined. The size, structure, and motion model of the WLLS are determined, and the slope inclination of the platform when the WLLS is working is determined.

(2) ADAMS was used to simulate the motion of the 3DOFS, including the motion of a single degree of freedom, the motion of two degrees of freedom, and the motion of three degrees of freedom. The firstdegree-of-freedom movement angle is $45^{\circ}$, the second-degree-of-freedom movement angle is $47^{\circ}$, and the third-degree-of-freedom movement angle is $60^{\circ}$. The three-degree-of-freedom movements are independent of each other. The movement of the wheel and leg structure is analyzed. The lifting height of the wheel-leg is up to $187 \mathrm{~mm}$, and the height of the centroid lifting is up to $244 \mathrm{~mm}$. In the extreme position, the inclination of the platform is reduced by $12.3^{\circ}$. During both the two-wheeled obstacle and the one-sided obstacle tests, the structure stably climbed over $170 \mathrm{~mm}$ obstacles.

(3) The functionality and achievability of the key components are determined. The theoretical model of the component is verified, ensuring that the key components designed can achieve the corresponding functions and that the corresponding performance can also be achieved. The experimental results show that the key components can achieve stable movement, which proves the feasibility of the design.

(4) The steering and lifting mechanisms are mainly applied to the forestry operations chassis. The steering mechanism can be used as an intermediate hinge structure for connecting a chassis having a towing property. The lifting structure can be used as a self-leveling structure to improve the road surface profile and obstacle stability. In the future forest operations, it must be mechanized operations and production to replace human activities. The forestry obstacle chassis with the steering and lifting mechanism will become the main loading platform for carrying equipment to work.

\section{Data Availability}

The data used to support the finding of this study are included within the article.

\section{Conflicts of Interest}

The authors declare that there are no conflicts of interest with respect to the research, authorship, and/or publication of this article.

\section{Acknowledgments}

This work was supported by the Fundamental Research Funds for the Central Universities (Grant no. 2015ZCQ-GX01) and Beijing Municipal Construction Project Special Fund.

\section{References}

[1] H. Lideskog, M. Karlberg, and U. Bergsten, "Development of a research vehicle platform to improve productivity and valueextraction in forestry," Procedia CIRP, vol. 38, pp. 68-73, 2015.

[2] A. Ismoilov, U. Sellgren, K. Andersson, and B. Löfgren, “A comparison of novel chassis suspended machines for sustainable forestry," Journal of Terramechanics, vol. 58, pp. 59-68, 2015.

[3] M. Arkadiusz, T. Czapla, and W. Klein, "Numerical simulation of active track tensioning system for autonomous hybrid vehicle," Mechanical Systems and Signal Processing, vol. 89, pp. 108-118, 2017.

[4] I. Kim, W. Jeon, and H. Yang, "Design of a transformable mobile robot for enhancing mobility," International Journal of Advanced Robotic Systems, vol. 14, no. 1, pp. 1-14, 2017.

[5] X. Xie, F. Gao, C. Huang, and W. Zeng, "Design and development of a new transformable wheel used in amphibious all-terrain vehicles (A-ATV)," Journal of Terramechanics, vol. 69, pp. 45-61, 2017.

[6] J. Pijuan, M. Comellas, M. Nogués, J. Roca, and X. Potau, "Active bogies and chassis levelling for a vehicle operating in 
rough terrain," Journal of Terramechanics, vol. 49, no. 3-4, pp. 161-171, 2012.

[7] J. Edlund, E. Keramati, and M. Servin, "A long-tracked bogie design for forestry machines on soft and rough terrain," Journal of Terramechanics, vol. 50, no. 2, pp. 73-83, 2013.

[8] Y. Zhang and T. Huang, "Research on a tracked omnidirectional and cross-country vehicle," Mechanism and $\mathrm{Ma}$ chine Theory, vol. 87, pp. 18-44, 2015.

[9] J. Kim, C. Lee, and G. Kim, "Study of machine design for a transformable shape single-tracked vehicle system," Mechanism and Machine Theory, vol. 45, no. 8, pp. 1082-1095, 2010.

[10] Z. B. Sun and J. H. Liu, "Stability analysis and gait planning for luffing wheel-legged robot during intelligent obstaclesurmounting process," Transactions of the Chinese Society of Agricultural Engineering, vol. 31, pp. 1-7, 2015.

[11] X. J. Yao, F. Gao, Y. Zhou et al., "Analysis of obstacles climbing performance for diameter-variable wheel all-terrainvehicle," Transactions of the Chinese Society of Agricultural, vol. 44, pp. 6-10, 2015.

[12] G. Y. Ge and Y. J. Wang, "On obstacle crossing research for quadruped eccentric wheel-legged robot," Journal of Southwest China Normal University (Natural Science Edition), vol. 39, pp. 96-99, 2014.

[13] E. Ottaviano and P. Rea, "Design and operation of a 2-DOF leg-wheel hybrid robot," Robotica, vol. 31, no. 8, pp. 13191325, 2013.

[14] H. Wang, J. Shi, J. Wang, H. Wang, Y. Feng, and Y. You, "Design and modeling of a novel transformable land/air robot," International Journal of Aerospace Engineering, vol. 2019, Article ID 2064131, 10 pages, 2019.

[15] M. Ning, B. Xue, Z. Ma et al., "Design, analysis, and experiment for rescue robot with wheel-legged structure," Mathematical Problems in Engineering, vol. 2017, Article ID 5719381, 16 pages, 2017.

[16] M. Ning, L. Shao, F. Chen, M. Li, C. Zhang, and Q. Zhang, "Modeling and analysis of a modular multilegged robot with improved fault tolerance and environmental adaptability," Mathematical Problems in Engineering, vol. 2019, Article ID 8261617, 17 pages, 2019.

[17] C. Zheng, J. Liu, T. E. Grift et al., "Design and analysis of a wheel-legged hybrid locomotion mechanism," Advances in Mechanical Engineering, vol. 7, no. 11, 2015.

[18] T. Sun, X. Xiang, W. Su, H. Wu, and Y. Song, "A transformable wheel-legged mobile robot: design, analysis and experiment," Robotics and Autonomous Systems, vol. 98, pp. 30-41, 2017.

[19] J. Faigl and P. Čížek, "Adaptive locomotion control of hexapod walking robot for traversing rough terrains with position feedback only," Robotics and Autonomous Systems, vol. 116, pp. 136-147, 2019.

[20] L. Bruzzone and G. Quaglia, "Review article: locomotion systems for ground mobile robots in unstructured environments," Mechanical Sciences, vol. 3, no. 2, pp. 49-62, 2012.

[21] A. Seeni, B. Schafer, B. Rebele, and N. Tolyarenko, "Robot mobility concepts for extraterrestrial surface exploration," in Proceedings of the IEEE Aerospace Conference, IEEE, Piscataway, NJ, USA, pp. 1-14, March 2008.

[22] L. Bruzzone and P. Fanghella, "Functional redesign of Mantis 2.0, a hybrid leg-wheel robot for surveillance and inspection," Journal of Intelligent \& Robotic Systems, vol. 81, no. 2, pp. 215-230, 2016.

[23] S. D. Herbert, A. Drenner, and N. L. Papanikolopoulos, "A Quadruped-hybrid stair climbing robot," in Proceedings of the
IEEE Conference on Robotics and Automation, IEEE, San Francisco, CA, USA, pp. 19-23, May 2008.

[24] G. Quaglia, L. Bruzzone, R. Oderio, and R. Razzoli, "Epi.Q Mobile robots family," ASME International Mechanical Engineering, vol. 2011, pp. 1165-1172, 2011.

[25] Y. Zhu, J. Kan, W. Li, and F. Kang, "A novel forestry chassis with an articulated body with 3 degrees of freedom and installed luffingwheel-legs," Advances in Mechanical Engineering, vol. 10, no. 1, 2018.

[26] M. Iida, H. Nakashima, H. Tomiyama, T. Oh, and T. Nakamura, "Small-radius turning performance of an articulated vehicle by direct yaw moment control," Computers and Electronics in Agriculture, vol. 76, no. 2, pp. 277-283, 2011.

[27] Y. Zhu, J. Kan, W. Li, and F. Kang, "Strategies of traversing obstacles and the simulation for a forestry chassis," International Journal of Advanced Robotic Systems, vol. 15, no. 3, 2018.

[28] Q. Gao, F. Gao, L. Tian et al., "Design and development of a variable ground clearance, variable wheel track self-leveling hillside vehicle power chassis (V2-HVPC)," Journal of Terramechanics, vol. 56, pp. 77-90, 2014.

[29] P. Li and H. Xu, "Braking efficiency and stability of chassis braking system of combine harvester: the theoretical derivation and virtual prototype simulation," Mathematical Problems in Engineering, vol. 2019, Article ID 6713231, 18 pages, 2019.

[30] J. Niu, H. Wang, H. Shi et al., "Study on structural modeling and kinematics analysis of a novel wheel-legged rescue robot," International Journal of Advanced Robotic Systems, vol. 15, no. $1,2018$.

[31] G. Qiao, G. Song, Y. Zhang, J. Zhang, and Z. Li, “A wheellegged robot with active waist joint: design, analysis, and experimental results," Journal of Intelligent \& Robotic Systems, vol. 83, no. 3-4, pp. 485-502, 2015.

[32] K. Watanabe, J. Yamakawa, M. Tanaka, and T. Sasaki, "Turning characteristics of multi-axle vehicles," Journal of Terramechanics, vol. 44, no. 1, pp. 81-87, 2007.

[33] R. Janos, M. Sukop, J. Semjon et al., "Conceptual design of a leg-wheel chassis for rescue operations," International Journal of Advanced Robotic Systems, vol. 14, no. 6, 2017.

[34] Z. Xiu-qin, Y. Bo, Y. Chao, and X. Guan-neng, "Research on ABS of multi-axle truck based on ADAMS/car and matlab/ simulink," Procedia Engineering, vol. 37, pp. 120-124, 2012.

[35] P. Ayers, J. B. Conger, R. Comer, and P. Troutt, "Stability analysis of agricultural off-road vehicles," Journal of Agricultural Safety and Health, vol. 24, no. 3, pp. 167-182, 2018. 